\title{
Una propuesta de objetivismo ético para contrarrestar la posverdad en la era de la cuarta revolución industrial
}

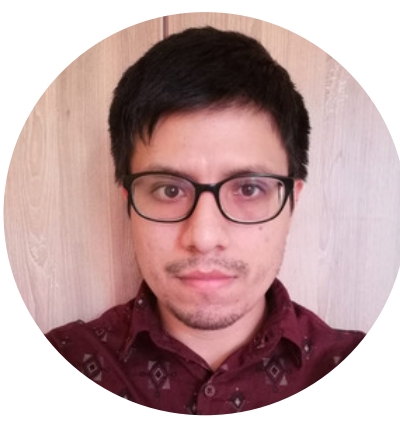

\section{JULIO SILVA CÉSPEDES iD https://orcid.org/0000-0002-0931-7528}

Estudiante de Filosofía en la Universidad Nacional Mayor de San Marcos. Miembro del instituto de extrapolítica y transhumanismo (IET) y del grupo de investigación Sentido y Referencia (UNMSM). Principales áreas de investigación: historia de la filosofía, filosofía de la mente, lógica y ética. Ha expuesto sus trabajos en eventos como el XVII Congreso Nacional de Filosofía (2019), el Primer Simposio Internacional de Lógica (2019) y el VIII Coloquio de Filosofía Latinoamericana (2020).

\section{julio.silva9@unmsm.edu.pe $\triangleright$ Filosofarte}

\section{El relativismo moral}

Generalmente, se suele creer que el hecho de que diferentes culturas tengan diferentes códigos morales implica que no es posible un objetivismo moral. Así, por ejemplo, si una cultura A considera que el aborto es incorrecto en toda circunstancia $y$, por otro lado, una cultura B considera que el aborto puede ser correcto en ciertas circunstancias, entonces de este hecho se podría deducir que no hay un enunciado moral objetivo en este asunto. Este argumento se puede presentar de forma general (Rachels, 2015):

Premisa) Diferentes culturas tienen diferentes códigos morales.

Conclusión) No hay enunciados morales objetivos. Lo correcto o incorrecto es una cuestión de opinión, y las opiniones varían de cultura a cultura.

Este argumento, al que llamaremos argumento de las diferencias morales entre las culturas, es persuasivo, pero es inválido: la conclusión no se sigue a partir de la premisa. Para entender esto, veamos la siguiente analogía: el hecho de que algunas culturas estén en desacuerdo sobre la forma de la Tierra no se deduce que no haya una verdad objetiva sobre la forma de ésta. Así, el problema con este argumento es que la premisa expresa lo que las culturas creen pero la conclusión, sin embargo, tiene que ver con lo que realmente sucede. No obstante, esto no significa que la conclusión del argumento sea falsa: la conclusión podría ser verdadera, a pesar de que el argumento es inválido. El punto importante es que la conclusión no se sigue a partir de la premisa. Esto nos lleva a discutir el asunto de cuán profundos son realmente los desacuerdos entre las diferentes culturas respecto de la moral.

\section{Creencias morales vs. creencias no-morales}

Ya hemos visto que es un hecho que los juicios sobre lo moralmente correcto varían de cultura a cultura. Ahora bien, es importante tener en cuenta que las personas podrían diferir en sus juicios morales no porque aceptan diferentes principios morales, sino porque sostienen diferentes creencias no-morales, es decir, creencias sobre cuestiones fácticas. Volviendo al ejemplo del debate sobre el aborto, las personas que se oponen a esta práctica generalmente presentan argumentos de la siguiente forma:

a) Asesinar a una persona inocente es moralmente incorrecto (premisa moral)

b) El feto es una persona (premisa fáctica)

c) Por lo tanto, asesinar a un feto (abortar) es moralmente incorrecto (conclusión moral)

En este caso, difícilmente habría desacuerdo con la premisa moral, pues hasta parece una tautología señalar que, efectivamente, asesinar a una persona inocente es moralmente incorrecto. Las personas que debaten este tema entran en desacuerdo con respecto a la premisa fáctica, y esta es una premisa no-moral, una premisa que trata de dar cuenta de un hecho. Así, pues, esta disputa sobre el aborto no presupone una disensión de creencias morales, sino una discrepancia sobre creencias no-morales. Este mismo razonamiento se podría aplicar a otros debates éticos para encontrar hipótesis morales plausibles, pues es razonable suponer que un con- 
junto de valores morales debe ser necesariamente universales, dado que permiten que las sociedades subsistan. Por ejemplo, supongamos que haya una sociedad en la cual no está prohibido el asesinato de personas inocentes: esa sociedad perecería rápidamente. Entonces, se puede concluir que los conflictos morales surgen no porque existan discrepancias entre creencias morales (pues hay premisas morales aceptadas universalmente, dado que permiten la subsistencia de las sociedades), sino porque hay discrepancias sobre creencias fácticas, es decir, creencias no-morales.

\section{El pensamiento crítico y la justificación de hipótesis morales}

Ya hemos visto que los problemas éticos surgen no por discrepancias entre creencias morales, sino por diferencias entre creencias fácticas. Así, se puede sugerir que hay al menos dos maneras de contrarrestar las discrepancias entre creencias fácticas para poder lograr un objetivismo moral: a) incentivar el pensamiento crítico, y b) tratar a las hipótesis morales de manera análoga a como se tratan las hipótesis científicas.

El pensamiento crítico reduciría la propensión a defender tesis relativistas. Una de las muestras más actuales de relativismo es la posverdad. Este término hace referencia a las situaciones en las que los hechos objetivos no son decisivos al momento de formar opiniones públicas. La era de la posverdad trae consigo noticias falsas, irrelevancia de la verdad, el conocimiento, la investigación y los hechos, y mucha ligereza al momento de hacer afirmaciones. Así, se podrían hacer afirmaciones sin ofrecer pruebas en favor de tales afirmaciones (Villena, 2019). Tratar de contrarrestar la posverdad es uno de los grandes retos para la Cuarta Revolución Industrial que se vive actualmente, pues esta nos permite una comunicación instantánea y, a su vez, una exposición a muchas noticias falsas y pseudociencias. Cultivar el pensamiento crítico ayudaría a considerar que en un debate se debe exigir a los interlocutores pruebas que avalen sus afirmaciones. Entonces, se podría tener la consigna de que los hechos son decisivos en los debates, y esto podría tener como consecuencia apuntar a un objetivismo moral, dada la tesis defendida en este ensayo. Esta idea está acorde con lo que sostiene Hannah Arendt (1998): "El objeto ideal de la dominación totalitaria no es el nazi convencido o el comunista convencido, sino las personas para quienes ya no existen la distinción entre el hecho y la ficción (es decir, la realidad empírica) y la distinción entre lo verdadero y lo falso (es decir, normas del pensamiento)" (p. 379).

Por otra parte, ¿qué significa tratar a las hipótesis morales como hipótesis científicas? La justificación de teorías éticas tiene una estrecha relación con la confirmación de las teorías científicas. Una hipótesis científica puede acentuar su credibilidad y establecerse como verdadera (pero no completamente), aunque esto no la haría inmune a críticas futuras $y$, probablemente, a ser refutadas (Popper, 1977). De la misma manera, "una teoría ética es una teoría empírica si su grado de confirmación es conveniente para explicar ciertos fenómenos de un dominio especifico más simple y más exitosamente que sus competidores" (Cruzado, 2016, pág. 108). Entonces, las hipótesis morales se podrían tratar como si fueren hipótesis científicas en el siguiente sentido: si determinada hipótesis normativa es plausible y se aplica en la realidad, entonces se produce una disminución del sufrimiento de las personas o, al menos, no se genera un sufrimiento adicional del que ya existe. Así, pues, las justificaciones de las hipótesis morales serían, como en las ciencias naturales, justificaciones basadas en evidencia empírica. Por ejemplo, supongamos que nuestra hipótesis moral $\mathrm{H} 1$ es que el matrimonio homosexual es moralmente correcto. Ahora, podemos razonar de la siguiente manera: si la hipótesis moral $\mathrm{H} 1$ es correcta y se aplica en la realidad, entonces debe suceder que en las sociedades en donde se ha permitido el matrimonio homosexual ha disminuido el sufrimiento de las personas 0 , al menos, no se produce un mayor sufrimiento del que ya existe. Esta conclusión empírica se podría corroborar en la experiencia. Por tanto, si las consecuencias empíricas de la aplicación de la hipótesis moral no se cumplen en la realidad, entonces dicha hipótesis moral puede ser rechazada. Este mismo razonamiento falsacionista se da en la práctica científica.

El esquema general de esta propuesta sería el siguiente:

a) Si la hipótesis moral $\mathrm{H} 1$ es correcta y se aplica en la realidad -> a)ocurren los hechos a1, a2, ..., an.

b) No ocurren los hechos a1, a2, ..., an.

c) Entonces, la hipótesis moral H1 es incorrecta y no se debe aplicar en la realidad.

$Y$, por otro lado, si ocurren los hechos a1, a2, ..., an, entonces se puede asumir la verosimilitud de la 
hipótesis moral $\mathrm{H} 1$, al menos hasta que aparezca un falsador de dicha hipótesis.Así, pues, la corrección o verosimilitud de las hipótesis morales sería objetiva, en el sentido de que las consecuencias empíricas (los hechos) son objetivas e independientes de nuestras creencias y deseos.

\section{Conclusiones}

a) El argumento de las diferencias morales entre las culturas es inválido: el que existan diferentes códigos morales entre las culturas no implica que no existan enunciados morales objetivos.

b) La diversidad de estándares morales objetivos entre las culturas es aparente: las sociedades cuyos juicios morales entran en conflicto difieren no en creencias morales, sino en creencias no-morales (creencias fácticas).

c) Tratar de contrarrestar la posverdad es uno de los grandes retos para la Cuarta Revolución Industrial que se vive actualmente, pues esta nos permite una comunicación instantánea y, a su vez, una exposición a muchas noticias falsas y pseudociencias.

d) Hay dos maneras de contrarrestar las discrepancias entre creencias fácticas para poder lograr un objetivismo moral: 1) incentivar el pensamiento crítico, y 2) tratar a las hipótesis morales como hipótesis científicas.

\section{Referencias}

Arendt, H. (1998). Los orígenes del totalitarismo. Taurus. Cruzado, M. (2016). La naturalización de la Ética: su posibilidad e importancia [Tesis de licenciatura, Universidad Nacional Mayor de San Marcos]. Repositorio institucional. http://cybertesis.unmsm.edu.pe/bitstream/handle/20.500.1267

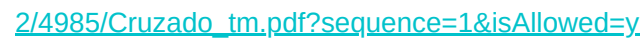

Popper, K. (1977). La lógica de la investigación científica. Tecnos. Rachels, J. (2015). The elements of moral philosophy (7a ed.). McGraw-Hill Education.

Villena, D. (2019). Era posverdad: Comunicación, política y filosofía. Psicopraxia, $1(1), \quad 17-26$ http://cesfia.org.pe/villena/posverdad_2019.pdf

\section{Cómo citar este artículo:}

Silva, J. (2021). Una propuesta de objetivismo ético para contrarrestar la posverdad en la era de la cuarta revolución industrial. Futuro Hoy, 2(1), 25-27. https://doi.org/10.5281/zenodo.4654888 